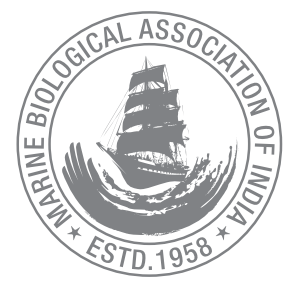

\title{
Seasonal abundance and diversity of finfish in a tropical estuary, Karwar, southwest coast of India
}

\author{
Navanath Kumbhar ${ }^{1 *}$, Sujitha Thomas² and Jayasree Loka ${ }^{3}$ \\ 'Mangalore University, Mangalagangotri, Mangalore, Karnataka-574 199. \\ ${ }^{2}$ Regional Centre of ICAR-CMFRI, Mangalore, Karnataka -575 001. \\ ${ }^{3}$ Regional Station of ICAR- CMFRI, Karwar-581 302. \\ *Correspondence e-mail: navanathkumbhar11@gmail.com
}

Received: 27 July 2020 Accepted: 08 Nov 2020 Published: 15 Nov 2020

Original Article

\begin{abstract}
The spatial and seasonal variability in finfish availability in the tropical Kali Estuary, in Karwar was studied from January 2017- May 2019 at three stations. A total of 26 species belonging to 9 orders and 20 families were recorded from the Kali Estuary and the order Perciformes with 16 species dominated the group (62\%) followed by order Mugilliformes and Pleuronectiformes (8\%). Maximum abundance was observed during the pre-monsoon season in all the stations. Excluding Ambassis ambassis which was abundant in all the stations, Caranx ignobilis dominated in all the stations. Truly marine and estuarine species of fishes recorded dominated than the freshwater estuarine ones like Etroplus suratensis, Scatophagus argus, Aplocheilus lineatus. Number of species recorded at each station during the study ranged from 11 to 25 and it was significantly different between stations. The Shannon- Wiener diversity index ranged from 2.0 to 4.6, the minimum in station 1 and maximum in station 3. The seasonal analysis of diversity also showed minimum value during the monsoon season in station 1 and maximum value in station 3. The minimum value (2.2) of Margalef richness index was also recorded in Station 1 during monsoon season and maximum value (4.2) in Station 2 . When comparing the relative abundance using Pielou's evenness index $\left(J^{\prime}\right)$ the values were in the range of 0.92 to 0.99 which was closer to one, indicating evenness in distribution. There was similarity in species composition according to
\end{abstract}

different seasons except for monsoon season in Station 1. The same pattern was also evident in the MDS plot where seasonal aggregation was observed between the stations. In addition to the diversity studies, the surveys also threw light on the abundance and seasonality of candidate species suitable for mariculture like $C$. ignobilis, Lutjanus spp., Etroplus spp., etc. Judicious exploitation of the species could help brackishwater fish farmers.

Keywords: Biodiversity, estuarine health, Kali Estuary, monsoon season, Shannon-Weiner Index

\section{Introduction}

Estuaries are a dynamic ecosystem which are often characterised by the presence of a high abundance and diversity of marine fishes and shellfishes (Haedrich, 1983; Elliott and Dewailly, 1995). They are one of the most biologically productive and valuable ecosystems which provide nursery ground to many marine species (Able, 2005; Beck et al., 2001). The coastal areas of India with its estuaries and mangroves provides shelters to many finfishes and shellfishes (Pushparajan et al., 2012). Estuaries play an important role in the life cycle of many fishes and shellfishes (Barletta et al., 1998, 2005). Distribution of 
fishes in estuaries are studied around the globe which is used as a baseline information which could be used for analysing the changes over a period of time due to anthropogenic and climatic disturbances (Barletta et al., 2005). Moreover, the finfish diversity study is one of the ways of assessing the state of health of the estuary (Bhat et al., 2014). India has around 200 estuaries among which Kali Estuary, in Karnataka is one of them (Balasubramanian et al., 2002). The rivers of Karnataka flows east to west and all the rivers join Arabian Sea to form large estuaries along coastal Karnataka (Rao et al., 1989). The Kali Estuary located in the northernmost part of Uttara Kannada one of the three coastal district in Karnataka comprise of different types of habitats like mangroves, brackishwater, creeks and freshwater zones. Various biological studies done in Kali Estuary are limited to the studies of crustaceans, mangroves etc. (Naik, 2003; Roopa et al., 2011; Loka et al., 2016). The studies on seasonal abundance and diversity in finfishes in Kali Estuary is limited. Therefore, the present study is taken up to address the spatial and seasonal variability in finfish availability in Kali Estuary.

\section{Material and methods}

Kali Estuary (14 $50^{\prime} 21^{\prime \prime} \mathrm{N} ; 74^{\circ} 09^{\prime} 05^{\prime \prime} \mathrm{E}$, Fig. 1.) situated in the south-west coast of India is one of the productive ecosystems in Uttara Kannada, Karnataka. The estuary is dynamic in nature which is strongly influenced by the monsoon and fluctuations in the salinity are observed based on the freshwater flow during monsoon showers (Balasubramanian and Khan 2002).

The present study was conducted from January 2017 to May 2019 for a period of 29 months. Three stations were selected in the estuary (Fig. 1) for the collection of finfishes, station 1 was near the barmouth area and station 3 the farthest point of collection with station 2 in between. Collection of finfishes was done during low tide biweekly using a cast net of $5 \mathrm{~m}$ diameter with $16 \mathrm{~mm}$ mesh and each cast net hauling covering an area of $20 \mathrm{~m}^{2}$. Three hauls were done at each station and the total finfishes caught were pooled for each station. The samples collected were cleaned, sorted and segregated. Total catch was recorded from each station. The segregated samples were identified to species level (Fischer and Bianchi, 1984; Froese and Pauly, 2017). Abundance was expressed as the average number per haul. The data collected for the study period was pooled and were categorised into four seasons namely premonsoon (Feb- May), monsoon (June-Sept), post-monsoon (Oct-Jan) (Thomas et al., 2016).

For statistical analysis multivariate statistical tests and ordinations were used to determine the patterns of community structures

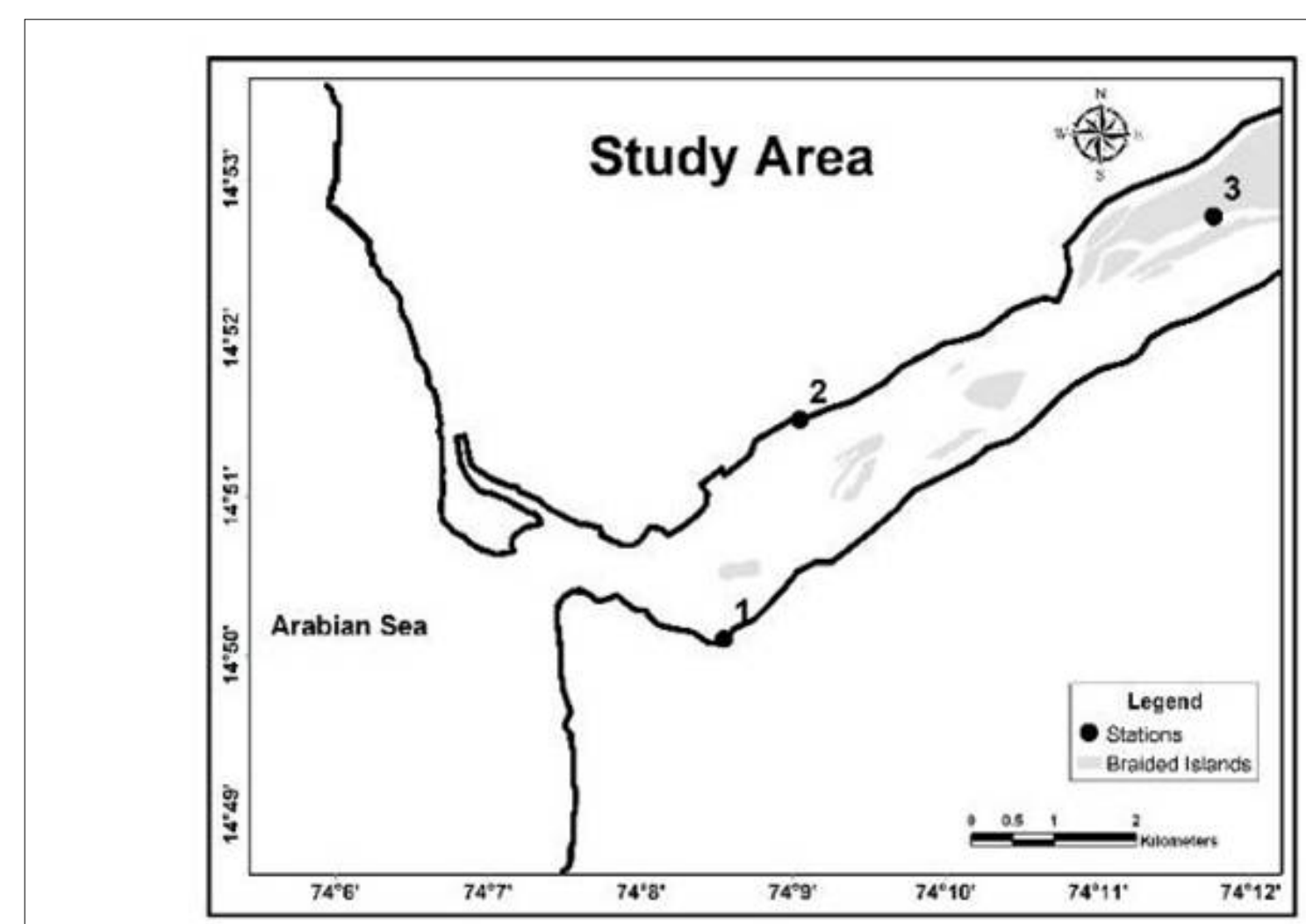

Fig. 1. Study area in Kali Estuary, Karnataka and sampling stations 
using the statistical package, Primer v6 proposed by Clarke and Warwick (2001). This was used for calculating diversity indices (Shannon Weiner indices), SIMPER, hierarchical cluster analysis and non-metric multidimensional scaling (MDS). The square roots of the standardised abundances were used to reduce the considerable influence of the highly abundant species in the community analysis. The multivariate non-metric MDS technique was used to identify seasonal variations in fish composition based on Bray-Curtis similarity. MDS is an unconstrained ordination technique used to create graphical summaries of the relationships among samples based on the abundance of various species present and to highlight the spatial and temporal patterns of the community structure (Clarke and Warwick, 2001). The similarity in species between the seasons was analysed employing similarity percentage (SIMPER) analysis using species abundance data. MDS and SIMPER were carried out in Primer v6 software (Clarke and Warwick, 2001).

\section{Results and discussion}

A total of 26 species belonging to 9 orders and 20 families were recorded from the Kali Estuary during the period of study. The order Perciformes with 16 species dominated the group (62\%) followed by order Mugilliformes and Pleuronectiformes (8\%) Other orders were of lesser numbers in species representation. Since there was no significant variation between months, the data was pooled to different seasons viz., pre-monsoon, monsoon and post-monsoon for further analysis. The details of the species collected from three stations are given in Table 1. Maximum abundance was observed during the pre-monsoon season in all the stations.

From Gangolli Estuary which is in Udupi District of Karnataka, about 30 species of finfishes were recorded by Rajesh et al. (2015). About 24 species of finfishes were recorded from Kali

Table 1. Season-wise and station-wise fish species collected from the Kali Estuary.

\begin{tabular}{|c|c|c|c|c|c|c|c|c|c|c|c|}
\hline \multirow[t]{2}{*}{ Order } & \multirow[t]{2}{*}{ Family } & \multirow[t]{2}{*}{ Scientific name } & \multicolumn{4}{|c|}{ Station 1} & \multicolumn{2}{|c|}{ Station 2} & \multicolumn{3}{|c|}{ Station 3} \\
\hline & & & $\operatorname{Pr}$ & M & $\mathrm{Pm}$ & $\operatorname{Pr}$ & M & $\mathrm{Pm}$ & $\operatorname{Pr}$ & M & $\mathrm{Pm}$ \\
\hline Mugiliformes & Mugilidae & Mugil cephalus & + & - & - & - & + & + & - & + & + \\
\hline Perciformes & Lutjanidae & Lutjanus argentimaculatus & + & + & + & + & + & + & - & + & + \\
\hline Perciformes & Lutjanidae & Lutjanus johnii & + & + & + & + & + & + & - & + & + \\
\hline Carangiformes & Carangidae & Caranx ignobilis & + & - & + & + & + & + & + & + & + \\
\hline Perciformes & Lethrinidae & Lethrinus lentjan & + & + & + & - & - & - & + & + & + \\
\hline Pleuronectiformes & Psettodidae & Psettodes erumei & - & - & - & + & + & + & + & + & + \\
\hline Pleuronectiformes & Cynoglossidae & Cynoglossus puncticeps & + & + & - & - & + & + & + & + & + \\
\hline Cyprinodontiformes & Aplocheilidae & Aplocheilus lineatus & - & - & - & + & + & + & + & + & - \\
\hline Beloniformes & Hemiramphidae & Hyporhamphus limbatus & + & + & + & + & + & + & + & + & + \\
\hline Scorpaeniformes & Platycephalidae & Platycephalus indicus & + & - & - & + & + & + & + & + & - \\
\hline Perciformes & Ambassidae & Ambassis ambassis & + & + & + & + & + & + & + & + & + \\
\hline Perciformes & Serranidae & Epinephelus diacanthus & - & - & + & - & - & + & + & + & - \\
\hline Perciformes & Terapontidae & Terapon jarbua & + & + & - & - & + & + & + & + & + \\
\hline Perciformes & Terapontidae & Terapon puta & - & - & - & - & + & - & + & + & + \\
\hline Perciformes & Leiognathidae & Leiognathus bindus & + & - & + & + & - & - & + & + & - \\
\hline Perciformes & Leiognathidae & Leiognathus blochii & + & - & + & + & - & + & + & + & - \\
\hline Perciformes & Gerreidae & Gerres limbatus & - & - & + & - & + & + & + & + & - \\
\hline Perciformes & Gerreidae & Gerres filamentosus & - & + & + & - & + & + & + & + & - \\
\hline Perciformes & Sparidae & Rhabdosargus sarba & - & - & - & - & + & + & - & + & + \\
\hline Perciformes & Scatophagidae & Scatophagus argus & + & - & - & + & + & - & + & + & - \\
\hline Cichliformes & Cichlidae & Etroplus suratensis & + & - & - & + & + & - & + & + & - \\
\hline Mugiliformes & Mugilidae & Liza parsia & + & + & + & + & + & + & - & - & - \\
\hline Perciformes & Siganidae & Siganus vermiculatus & - & - & - & - & + & + & - & + & + \\
\hline Perciformes & Siganidae & Siganus javus & - & - & - & - & + & + & - & + & + \\
\hline Clupeiformes & Engraulidae & Stolephorus commersonnii & - & + & - & + & + & - & - & + & + \\
\hline Perciformes & Sillaginidae & Sillago sihama & + & + & + & + & + & + & - & + & + \\
\hline
\end{tabular}

+ Presence, -. Absence, M Monsoon, Pm Post-monsoon, Pr Pre-monsoon 
Estuary during 2016 survey (Loka et al., 2016). However, it is lower than the reports of 46 species (Naik, 2003) and 37 species (Roopa et al., 2011) from Kali Estuary during surveys done during 2003 and 2011. The species diversity recorded from Zuari Estuary was comparatively high (more than 200) when compared to the present study. The greater diversity is attributed to the diverse habitat characteristics including sandy, rocky, muddy and coral which attracts diverse fish assemblages to this estuary (Sreekanth et al., 2016). Comparing the results of small and large estuarine surveys from different locations worldwide, it was observed that the species composition is never large. About 23 species were recorded from Mystic river estuary by Haedrich and Haedrich (1974). Strydom and Whitefield (2000) recorded 30 species from Kromme Estuary in South Africa. The reasons for less number in the present study could be due to the sampling methods used in various study including gillnets and seine nets, whereas in the present study the cast net was used. Another reason for the low diversity when compared to the previous studies in same estuary during 2003 and 2011 could be due to various anthropogenic activities including sand mining occurring in the estuary.

When considering the overall abundance of the species in three stations, it was observed that Ambasis ambasis was the most abundant species in the estuary throughout all the seasons and stations. Excluding A. ambasis, Caranx ignobilis dominated in all the stations and contributed 24, 14 and 15\% in Stations 1, 2 and 3 respectively. Following C. ignobilis, Liza parsia (13\%) dominated in Station 1, Scatophagus argus (8\%) in Station 2 and Gerres limbatus (6\%) in Station 3 (Fig. 2).

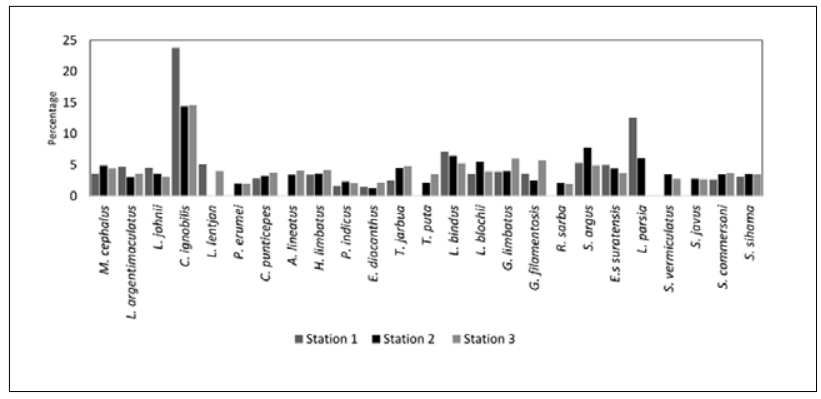

Fig. 2. Percentage composition of species in three stations in Kali Estuary

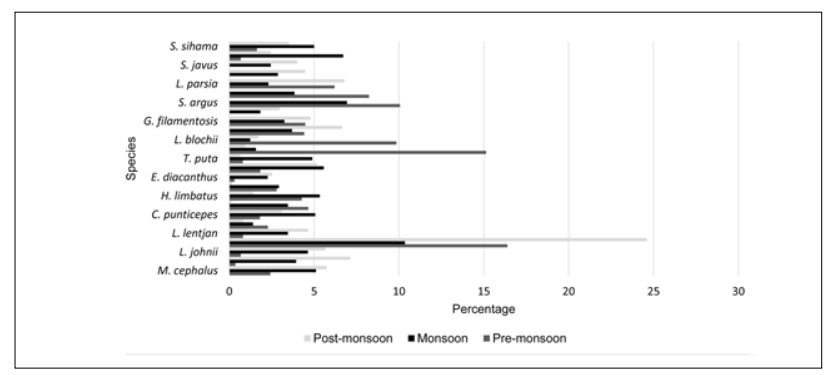

Fig. 3. Seasonal species composition of finfishes in Kali Estuary

were reported by Kantoussan et al. (2012), Murugan et al. (2014), Rajesh et al. (2015). All the dominating species in the survey are commonly reported from the survey conducted in various estuaries across the country (Murugan et al., 2014; Rajesh et al., 2015; Bhat et al., 2014, 2016). However, variations in the species composition has to be studied at regular intervals to assess the health of the estuarine ecosystem which is a nursery grounds to many of the marine species (Barletta et al., 2005).

The number of species recorded increased from the barmouth area to the interior. Number of species recorded during the survey ranged from 11 to 25 and it was significantly different between stations ( $p<0.01$ ). In station 1 minimum number of species (11) was recorded during monsoon season while maximum number of 16 species was recorded during pre-monsoon season. In station 2 and 3 maximum number of species 22 and 25 respectively was observed during monsoon season. Minimum number of species (16) was observed during pre-monsoon period in station 2 and 16 numbers in post monsoon period in Station 3. The diversity increased from Station 1 to station 3, The Shannon- Wiener diversity index $\left(\mathrm{H}^{\prime} \log _{2}\right)$ ranged from 2.0 to 4.6 , the minimum in station 1 and maximum in station 3 (Fig. 4).

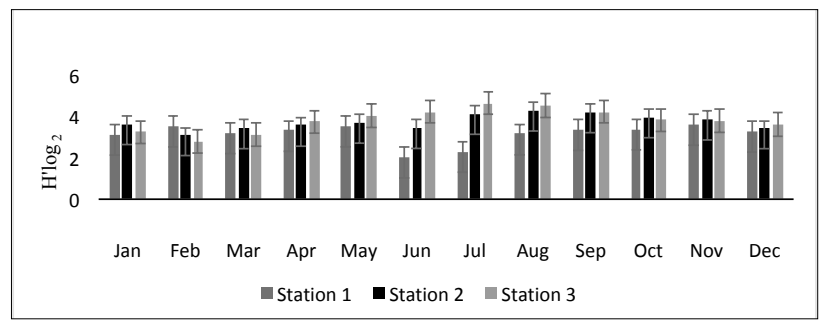

Fig. 4. Shannon Weiner diversity $\left(H^{\prime} \log _{2}\right)$ index in three stations in Kali Estuary

There was significant difference in diversity between stations $(p<0.01)$. The seasonal analysis of Shannon-Weiner diversity index also showed minimum value during the monsoon season in station 1 and maximum value in the station 3 . The minimum value (2.2) of Margalef richness index was also recorded in Station 1 during monsoon season and maximum value (4.2) in Station 2 (Fig. 5). When comparing the relative abundance using Pielou's evenness index $\left(J^{\prime}\right)$, the values were in the range 
of 0.92 to 0.99 which is closer to one indicating evenness in distribution. The Shannon- Wiener diversity index values reported from the present study is within the range of the diversity values reported in the studies from estuaries in different regions. The values in these estuaries ranged from 0.99 to 5.8 . The evenness in distribution of the estuarine species were same as that observed in similar studies (Najim and Yousef, 1990, Pushparajan et al., 2012, Srilatha et al., 2013, Murugan, 2014, Rajesh et al., 2015).

The monsoon season in station 2 and 3 had maximum diversity, in contrast to the studies conducted in other estuaries in India, where the diversity was high during pre-monsoon or post monsoon period (Murugan et al., 2014; Rajesh et al., 2015; Bhat et al., 2014, 2016). The exact reasons which regulate the diversity and species composition in the estuaries is not clearly defined. The species are influenced by salinity gradients in estuary (Barletta et al., 2005) and to a lesser extent to the substratum characteristics (Weinstein et al., 1980). The estuaries along the Indian coast are highly influenced by rainfall during monsoon season. The heavy downpour combined with the high runoff from the rivers influence the species distribution and abundance in the estuary (Shetye, 2011). Kali Estuary is very much influenced by the southwest monsoon and when the intensity of the rain is more the salinity falls to nearly 0

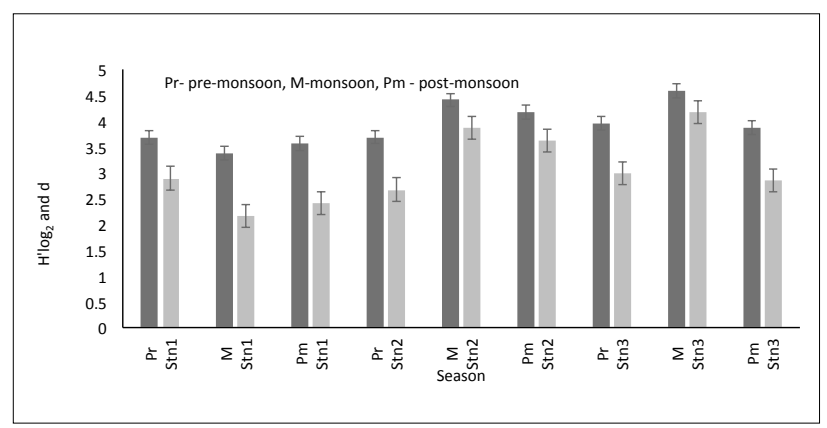

Fig. 5. Seasonal Shannon Weiner Diversity $\left(\mathrm{H}^{\prime} \log _{2}\right)$ and Margalef richness index (d) in Kali Estuary

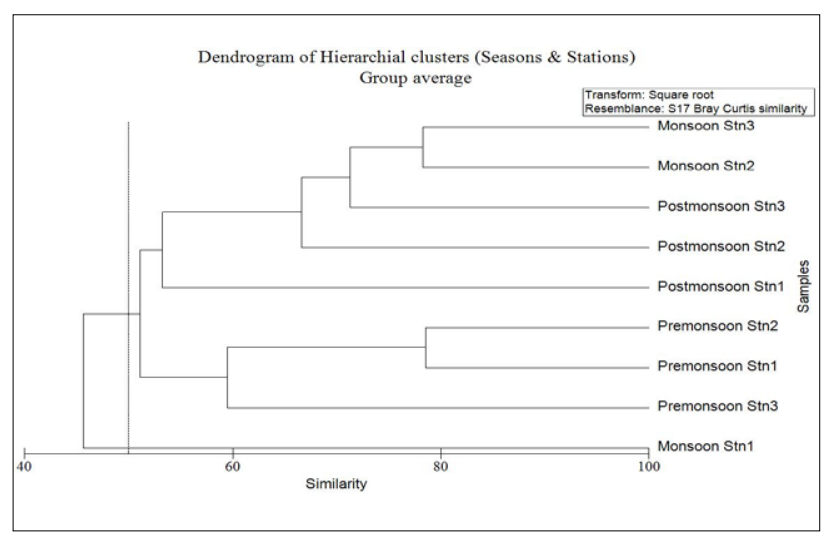

Fig. 6. Dendrogram of Hierarchical clustering (group-average linking) for the finfish collected from three stations during various seasons ppt. In the present study, station 1 is nearer to the barmouth where the water is a bit shallow, with less mangrove vegetation and other anthropogenic activities like sand mining, and clam picking are rampant in this station. The other two stations are with good mangrove vegetation and deeper than station 1. The disturbances will be less in the two stations compared to station 1 which could be one of the reasons for less diversity and species in station 1 . The mangrove generally provides a well-protected area for the marine organisms to survive and thrive. (Shtye, 2011, Murugan, 2014).

Cluster analysis was done to study the grouping of stations belonging to various seasons (Fig. 6). Cluster analysis showed two major clusters. There was similarity in species composition according to different seasons except for monsoon season in Station 1. The first cluster was formed in the pre-monsoon season of three stations. The pre-monsoon composition of Station 1 and Station two showed maximum similarity (79\%) to which pre-monsoon of Station 3 got linked (58\%). The second cluster was formed with post-monsoon and monsoon seasons. The monsoon season of Station 2 and station 3 linked together with maximum similarity $(78 \%)$ to which the postmonsoon season Station 3, Station 2 and Station 1 got linked respectively. The species composition of monsoon season of Station 1 showed minimum similarity with other seasons and stations (average similarity of $46 \%$ ). The same pattern was also evident in the MDS plot (Fig. 7) where seasonal aggregation was observed between the stations. The stress value which was overlaying on the MDS plot (0.1) showed a good ordination of the samples collected.

Cluster analysis was helpful in finding out the natural grouping of samples such that similar groups forms one cluster (Clark and Warwick, 2001). In this study hierarchical method was used in cluster analysis. The similarity in hydrographic conditions

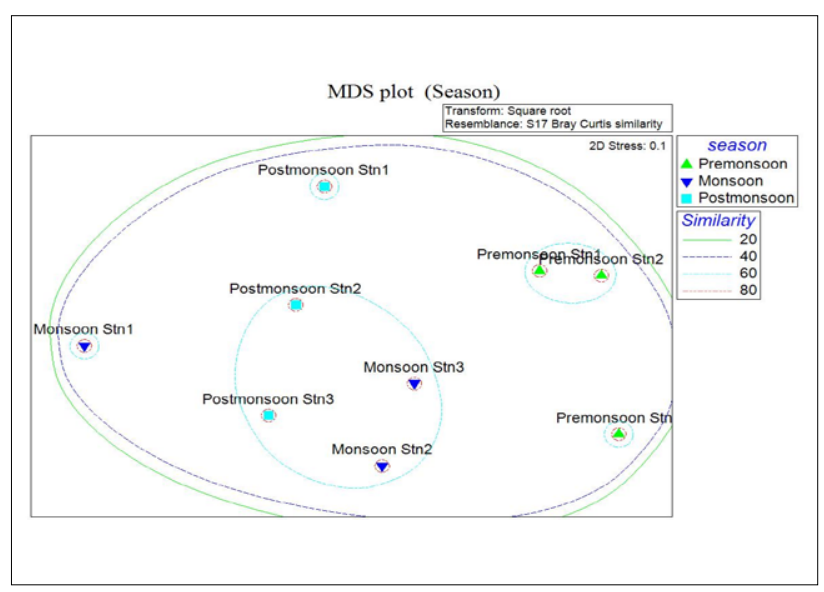

Fig. 7. MDS plot for finfish from various stations showing good ordination and goodness of fit. 
in different seasons would have led to the similarity in the species composition between different seasons. However, dissimilarity in the species composition during monsoon season in Station 1 could be due to the shallow water and the increased turbidity during the monsoon season near barmouth. The fishes tend to move towards areas where protection is available (Shtye, 2011), in this case the mangrove vegetation in station 2 and 3.

The present study in Kali Estuary throws light on the variations in the species diversity in different locations. It was observed that sand mining is rampant in Station 1 which could be the reason for less diversity in Station 1 . Also the mangrove vegetation which is absent in Station 1 and found in station 2 and 3 have helped in increasing the diversity in those zones. Environmental effects of various anthropogenic activities including sand mining cause changes in the rivers and estuaries which in turn could influence the biodiversity in the area. (Padmalal, 2008, Bhattacharya et al., 2020). In the present study also decreased diversity observed in Station 1 could be attributed to the sand mining, less mangrove vegetation and shallowness of the area Estuaries along the coast of India are subjected to increasing pressures from various anthropogenic activities and climate change (Lotze et al., 2006). The importance of the estuarine environment, which includes the mangroves and the nursery habitat of many marine organisms and the threats to which it is exposed have resulted in increased interest in this environment. (Colwell and Coddington, 1994). Through finfish diversity study an attempt is made to assess the health of the estuary, which is exposed to various anthropogenic activities. Hence similar studies in regular intervals are required to develop a strong database for the estuary to assess the impact of any interventions in the ecosystem. In addition to diversity studies, surveys also throw light on the abundance and seasonality of candidate species suitable for mariculture like $C$. ignobilis, Lutjanus spp., Etroplus spp., etc. and judicious exploitation of the species could help brackish water fish farmers.

\section{Acknowledgements}

The authors are thankful to the Director, ICAR-CMFRI, Kochi and Project Coordinator, All India Network Project on Mariculture (AINP-M; ICAR). Authors are also thankful to Scientist-In-charge, Karwar Research Centre of ICAR-CMFRI for the facilities provided for the work.

\section{References}

Able, K. W. 2005. A re-examination of fish estuarine dependence, evidence for connectivity between estuarine and ocean habitats. Est. Coast. Shelf. Sci., 64(1): 5-17.

Balasubramanian T. and S. Ajmal Khan. 2002. Estuaries of India. In: Balasubramanian, T. Ajmal Khan, S. (eds.). State-of-the-art-report., $95 \mathrm{pp}$.

Balasubramanian T., S. Ajmal Khan and N. Rajendran. 2002. Estuaries of India: State of the Art Report. Environmental Information System Centre. Centre of Advanced Study in Marine Biology. Annamalai University., p. 1 - 2, 138 - 145.

Barletta, M., A. Barletta Bergan and U. Saint-Paul. 1998. Description of the fishery structure in the mangrove dominated region of Braganca. (State of Para' ${ }^{-}$-North Brazil). Ecotropica., 4: 41-53

Barletta, M., A. Barletta-Bergan, U. Saint-Paul and G. Hubold. 2005. The role of salinity in structuring the fish assemblages in a tropical estuary. J. Fish. Biol., 66: 45-72.

Barletta, M., U. Saint Paul, A. Barletta Bergan, D. Ekau and W. Schories. 2000. Spatia and temporal distribution of Myrophis punctatus (Ophichthidae) and associated fish fauna in a Northern Brazilian intertidal mangrove forest. Hydrobiologia, 426: 65-74.

Beck, M. W., K. L. Heck, K. W. Able, D. L. Childers, D. B. Eggleston, B. M. Gillanders, B. Halpern, C. G. Hays, K. Hoshino, T. J. Minello, R. J. Orth, P. F. Sheridan and M. P. Weinstein. 2001. The identification, conservation and management of estuarine and marine nurseries for fish and invertebrates. BioScience., 51(8): 633-641.

Bhattacharya Raj Kumar, Nilanjana Das Chatterjee and Kousik Das. 2020. Impact of in stream sand mining on habitat destruction or transformation using coupling models of HSI and MLR. Spat. Inf. Res., 28: 67-85.

Clark, W. R. and R. M. Warwick. 2001. Change in marine communities. 2nd edition Primer-E Ltd, Plymouth.

Colwell, R. K. and J. A. Coddington. 1994. Estimating terrestrial biodiversity through extrapolation. R. Soc. Lond. Phil. Trans., 345: 101-118.

Haedrich, R. L. and S. O. Haedrich. 1974. A seasonal survey of the fishes in the Mystic river, a polluted estuary downtown Boston, Massachusetts. Est. Coastal Marine Sci., 2: 59-73.

Kantoussan, J., Jean Marc Ecoutin, Monique Simier, Luis Tito de Morais and Raymond Laë. 2012. Effects of salinity on fish assemblage structure. An evaluation based on taxonomic and functional approaches in the Casamance Estuary. (Senegal, West Africa). Est. Coastal Shelf Sci., 113: 152-162.

Lotze, H. K., H. S. Lenihan, B. J. Bourque, R. H. Bradbury, R. G. Cooke, M. C. Kay, S. M. Kidwell, M. X. Kirby, C. H. Peterson and J. B. C. Jackson. 2006. Depletion, degradation, and recovery potential of estuaries and coastal seas. Science, 312: 1806-1809.

Naik, A. 2003. Studies of fish seed resources of Kali Estuary Karwar, Karnataka, India. Ph.D. Thesis. Karnatak University., 230 pp.

Najim, K. A. and A. Y. Yousif. 1990. Composition, seasonality and abundance of fishes in the Shatt A1-Basrah canal, an estuary in Southern Iraq. Est. Coastal and Shelf Sci. 31(4): 411-421.

Padmalal, D., K. K. Maya, S. Sreebha and R. Sreeja. 2008. Environmental effects of river sand mining: A case from the river catchments of Vembanad Lake, southwest coast of India. Environ. Geol., 54(4): 879-889.

Pushparajan, N., P. Soundarapandian, P. S. Lyla, T. Anand and D. Varadarajan. 2012. Shrimp larval; ingress in Pitchavaram mangroves southeast coast of India. J. Appl. Sci. Res., 8: 1775-1786.

Roopa, S. V., J. L. Rathod and B. Vasanthkumar. 2011. Fin Fish Diversity in Kali Estuarine Ecosystem of Karwar, Karnataka. W. J. Sci. Tech., 1: 22-25.

Shetye R. Satish. 2011. Indian estuaries: Dynamics, ecosystems, and threats. NATL ACAD SCI LETT, 34: 7-8.

Sreekanth, G. B., S. K. Chakraborty, A. K. Jaiswar, and P. U. Zacharia. 2016. An inventory on the coastal finfish and shellfish species of Zuari Estuary, southwest coast of India. Indian. J. Mar. Sci., 47(5):945-958.

Strydom, N. A. and A. K. Whitfield. 2000. The effects of a single freshwater release in to the Kromme Estuary. 4: Larval fish response. Water SA., 26(3): 319-327.

Weinstein, M. P. S. L. Weiss and M. F. Walters. 1980. Multiple determinants of community structure in shallow marsh habitats, Cape Fear Estuary, North Carolina, USA. Mar. Biol., 58: 227-243. 